\title{
Non-Prescription Antibiotics Use and Associated Factors Among Drug Retail Outlets in Ambo, Ethiopia: A Cross-Sectional Study
}

\author{
Hika Ayana ' \\ Tesemma Sileshi iD ${ }^{1,2}$ \\ Mohammed Hussen Bule iD ${ }^{2}$ \\ Eshetu E Chaka (iD) ${ }^{3}$ \\ 'Department of Public Health, Rift Valley \\ University, Ambo, Ethiopia; ${ }^{2}$ Department \\ of Pharmacy, College of Medicine and \\ Health Sciences, Ambo University, Ambo, \\ Ethiopia; ${ }^{3}$ Department of Public Health, \\ College of Medicine and Health Sciences, \\ Ambo University, Ambo, Ethiopia
}

Correspondence: Mohammed Hussen Bule

Department of Pharmacy, College of

Medicine and Health Sciences, Ambo

University, P. o. Box: 653/III0, Addis

Ababa, Ethiopia

Tel +25। 911809397

Email mohammed2bule@gmail.com
Purpose: To assess the non-prescription use of antibiotics and associated factors in Ambo Town, West Shoa, Oromia, Ethiopia.

Methods: An institutional-based cross-sectional study design supported with the qualitative study was conducted in Ambo Town from February 1 to March 1, 2020. Data were collected using a pretested semi-structured questionnaire and in-depth interview guide questions. Simple random sampling was used to select retail outlets and systematic random sampling to select study participants. The data analysis was done using SPSS and univariate and multivariate binary logistic regression analysis was performed to identify factors associated with non-prescription use of antibiotics. Thematic framework analysis was applied for the qualitative data.

Results: From the 421 study sample, a total of 399 participants were interviewed with a $94.8 \%$ response rate. Among the study participants, 214 (53.6) were males, $228(57.1 \%)$ were married, 191 (47.9\%) were orthodox by religion, and $343(86 \%)$ were Oromo by ethnicity. One hundred seventy-two $(43.1 \%$; 95\% CI: 38.6, 48.1) of the participants had used non-prescribed antibiotics. Being male [AOR=2.21 95\% CI: $1.276,3.835]$, residing in rural area $[\mathrm{AOR}=3.659,95 \% \mathrm{CI}: 1.479,9.054]$, holding diploma $[\mathrm{AOR}=0.120,95 \% \mathrm{CI}$ : $0.025,0.591]$, and hold $\mathrm{BSC}$ degree [AOR $=0.050,95 \% \mathrm{CI}: 0.007,0.378]$, and being farmer $[\mathrm{AOR}=0.034,95 \% \mathrm{CI}: 0.004,0.285]$ showed significant association with the nonprescription use of antibiotics.

Conclusion: This study concluded that the non-prescription use of antibiotics 172 (43.1\%) was relatively high. Being male, residing in a rural area, holding a diploma, BSc degree, and being a farmer were significantly associated with non-prescription use of antibiotics. So, West Shoa Zone regulatory body should actively focus on the prevention of non-prescription use of antibiotics through health communication and public awareness on the demerits of non-prescription use of antibiotics.

Keywords: antibiotics, community pharmacy, drug store, non-prescription, Ambo

\section{Introduction}

Antibiotics are drugs prescribed for the treatment of infections and are prescribed most frequently worldwide. In this regard, the data in the decade from 2000 to 2010 show a sharp increase in the amount of consumed antibiotics from approximately 50 billion to 70 billion standard units. ${ }^{1}$ Although the use of antibiotics without prescription is prevalent worldwide everyone needs to know such a trend poses a great risk to the global public health in general and to the person taking it in particular. $^{2}$ The irrational use of antibiotics is the major factor for the emergence 
and spread of antimicrobial resistance (AMR). ${ }^{3}$ The most common forms of infections in the community including respiratory tract infections of viral origin are the reasons for irrational use of drugs mainly non-prescription antibiotics. $^{4}$

The health and economic impacts of antibacterial resistance are quite deleterious. Globally around 700,000 deaths per year have been triggered due to antibiotic resistance. The negative consequences of antibacterial resistance can increase associated deaths to about 10 million by 2050 and the related costs to be incurred might go as high as 100 trillion USD globally. ${ }^{5}$ The view that "medicines shall be consumed during any sickness or discomfort" is one among the various factors associated with the emergence of antimicrobial resistance. ${ }^{6}$ The use of non-prescribed antibiotic agents varies in relation to determinants $^{7}$ such as sex, age, marital status, occupation, income, religion, residence, and educational status, chronic diseases, ${ }^{8}$ severity of illness, ${ }^{9}$ and repeated exposure to disease. ${ }^{10}$ Moreover, prior experience with antibiotics, access to health care facilities, awareness about the drug, and previous successful antimicrobial drug use $e^{9,11}$ are also factors that determine the use of antibiotics without prescription. The use of non-prescribed antibiotics frequently results in adverse drug reactions and masking of the primary infection. ${ }^{12}$ Additionally, irrational use of drugs can be the reason for shorter treatment period, inadequate/ inconsistent doses, sharing of medicines, or quitting the drug upon the improvement of symptoms. ${ }^{13}$

Antibiotic resistance is an emerging global public health challenge in parts of the society where there is frequent use of non-prescribed antibiotics. ${ }^{14}$ Concerning this, the problem is even worse in the least developed countries (LDCs) like Ethiopia since the burden of infectious diseases is quite high and the healthcare spending of these countries is low. In Ethiopia, over-the-counter (OTC) use of antibiotics, use of partial doses, and use without prescription are common practices, though the drug regulation of the country does not allow that. ${ }^{15}$ A study conducted in Ethiopia's Tigray region revealed that the magnitude of non-prescribed antibiotic use was $47.1 \%{ }^{16}$ In addition to weak law enforcement by drug regulatory authorities, the misuse and overuse of antibiotics in Ethiopia has contributed to a higher incidence of antimicrobial resistance ranging from $0 \%$ to $100 \% .{ }^{17}$

Although self-medication is a worldwide problem, in LDCs including Ethiopia, there is fairly wide access to antibiotics without prescription and not much has been done to tackle the challenge. ${ }^{18}$ To make the problem even worse, the role of pharmacists as healthcare providers remains debatable since they are mostly considered as retailers and businessmen instead of healthcare professionals. ${ }^{2}$ Therefore, this study aims to assess the magnitude of the non-prescription sale of antibiotics and associated factors in Ambo Town, West Shoa Zone, Oromia, Ethiopia, in 2020.

\section{Materials and Methods Study Area}

The study was conducted in Ambo Town, West Shoa Zone, Oromia Regional State, Ethiopia. The town is located $114 \mathrm{~km}$ from the capital Addis Ababa. Based on the 2007 Ethiopian national population and housing census, the population of the town is projected to be about 86,405 . The town has both private (5 pharmacies and 27 drugstores) and governmental (5 pharmacies) where the prescription-only drugs and over-the-counter drugs are dispensed to the customers. Basically, in the Ethiopian context, the major difference between the drugstores and the pharmacies is that newer antibiotics are reserved for pharmacies.

\section{Study Design and Period}

A drug retail outlet-based cross-sectional study was conducted from February 1 to March 1, 2020.

\section{Study Population}

All the people who bought antibiotics, from randomly selected pharmacies and drug stores (drug retail outlets) in Ambo Town during the study period.

\section{Sample Size Determination}

The sample size was calculated using a single population proportion formula; considering a $5 \%$ margin of error, the proportion of non-prescription use of antibiotics was $47.1 \%$ obtained from a previous study done in Tigray [16], Ethiopia, 95\% confidence interval, and $10 \%$ possible non-response rate.

$$
n=Z^{2} \alpha / 2 \times p(1-p) / w^{2}
$$

where

$n=$ sample size.

$p=$ proportion of irrational use and non-prescription sale of antibiotics.

$w=$ maximum allowable error $($ margin of error $)=0.05$. 
$Z=$ value of the standard normal distribution (Z-statistic) at a $95 \%$ confidence level, which was 1.96 .

$$
n=1.96^{2} \times \frac{0.471(1-0.471)}{0.05^{2}}=383
$$

Then after a $10 \%$ nonresponse rate is considered the final sample size is 421 .

The sample size for the qualitative study was based on the saturation of ideas.

\section{Sampling Technique and Procedures}

A simple random sampling technique was used to select two pharmacies out of five and 8 drug stores out of 27 drug stores in the town. Then, the history of the number of antibiotic purchasers in January 2020 was assessed for each selected pharmacy and drug store. Based on the previous history data, systematic random sampling methods were used to select study participants from each selected pharmacy and drug store every third purchaser based on their drug retail outlet visit sequence at the exit. The first study subject was determined randomly by the lottery method. The sample size was allocated proportionally to each pharmacy or drug store.

\section{Operational Definition} Non-Prescription Antibiotic Use

Non-prescription-based inappropriate antibiotic use for the treatment of common infections without consulting a medical practitioner and any medical supervision.

\section{Drug Retail Outlet}

A place used for the conduct of the drug sale, administering or dispensing, and licensed by the responsible body as a place where the practice of pharmacy may lawfully occur.

\section{Data Collection Tool and Techniques}

Data were collected using a pretested and semi-structured questionnaire and in-depth interviews. The questionnaire was prepared in English based on the previous studies and translated to Afaan Oromo and Amharic then back to English to check for consistency and completeness.

The exit interview was conducted at the pharmacies or drug stores immediately after a person purchased antibiotics after getting consent. The interview was conducted by trained nurses who could speak Afaan Oromo and Amharic.

In-depth interviews of sellers were conducted using open-ended interview guide questions to explore factors related to the non-prescription use of antibiotics. The in- depth interview was supported by tape-recording which took 25-30 min on average. All the interviews were taken at locations that were chosen by the respondents.

\section{Data Quality Control and Management}

To ensure data quality, training on the topic, and purpose of the research, on how to approach study subjects, and how to use the questionnaire was given for 1 day for the data collectors. A pretest was conducted at pharmacy retail outlets found outside the study area to modify the questionnaire. The collected data were checked for completeness, accuracy, and clarity daily after data collection, and correction measure was made before the next data collection.

\section{Data Processing and Analysis}

Coding and cleaning of data were performed for completeness and consistency. Data were entered into Epi-Info version 7.1 and exported to SPSS version 24 software package for analysis. Descriptive statistics are presented as frequencies and percentages. The bivariate analysis was performed for each variable and those variables with a p-value less than 0.25 was a candidate for multiple binary logistic regressions. The binary logistic regression model was used to check the association between outcome and independent variables. Crude Odds Ratio (OR) and Adjusted Odds ratio (AOR) with their 95\% confidence interval (CI) was reported. All statistical significance was determined at a p-value less than 0.05 .

Qualitative data were analyzed using thematic framework analysis. ${ }^{19}$ The following six steps were conducted:

1. Transcriptions were carried out from the audiotaped interviews.

2. All transcripts were repeatedly read to familiarize with the data.

3. After careful reading, codes were developed so that similar codes were grouped into categories.

4. A working analytical framework was developed while grouping similar codes into categories.

5. Data were summarized by category from each transcript using a matrix spreadsheet, a process called charting.

6. Interpreting the data was the last step. Findings from patients and health professionals were triangulated. This helps to the validity of the data and shows conflicting views. 


\section{Results}

\section{Socio-Demographic Characteristics of Study Participants}

Out of the 421 study samples, a total of 399 participants were interviewed with a $94.8 \%$ response rate. The mean age of the study participants was $36.32(\mathrm{SD} \pm 16.32)$ years. Among the study participants, 214 (53.6) were males, 228 (57.1\%) were married, 191 (47.9\%) were orthodox by religion, and 291 (72.9) were urban residents. One-fourth of the participants were unable to read and write, while the remaining completed at least primary school (Table 1).

\section{Non-Prescription Antibiotic Use}

The magnitude of non-prescription use of antibiotics in the study area is $43.2 \%$ (95\% CI: $38.2,48.1)$. Amoxicillin is the

Table I Socio-Demographic Characteristics of the Study Participants ( $n=399)$

\begin{tabular}{|c|c|c|}
\hline Characteristics & Category & $n=399(\%)$ \\
\hline \multirow[t]{2}{*}{ Sex } & Male & $214(53.6)$ \\
\hline & Female & $185(46.4)$ \\
\hline \multirow[t]{5}{*}{ Age group (years) } & $18-27$ & $143(35.8)$ \\
\hline & $28-37$ & $85(21.3)$ \\
\hline & $38-47$ & $79(19.8)$ \\
\hline & $48-57$ & $39(9.8)$ \\
\hline & $>57$ & $53(13.3)$ \\
\hline \multirow[t]{3}{*}{ Marital status } & Single & $159(39.8)$ \\
\hline & Married & $228(57.1)$ \\
\hline & Others ${ }^{\mathrm{a}}$ & $12(3.0)$ \\
\hline \multirow[t]{3}{*}{ Religion afflation } & Orthodox & $191(47.9)$ \\
\hline & Protestant & $175(43.9)$ \\
\hline & Muslim & $33(8.3)$ \\
\hline \multirow[t]{2}{*}{ Residence } & Urban & $291(72.9)$ \\
\hline & Rural & $108(27.1)$ \\
\hline \multirow[t]{5}{*}{ Educational status } & No formal education & $85(21.3)$ \\
\hline & Primary school & $99(24.8)$ \\
\hline & Secondary school & $86(21.6)$ \\
\hline & Diploma & $62(15.5)$ \\
\hline & Degree and above & $67(16.8)$ \\
\hline \multirow[t]{7}{*}{ Occupational status } & Government & $8 I(20.3)$ \\
\hline & Merchant & $91(22.8)$ \\
\hline & Farmer & $74(18.5)$ \\
\hline & Housewife & $42(10.5)$ \\
\hline & Student & $13(5.7)$ \\
\hline & Non-employed & $2 \mathrm{I}(5.3)$ \\
\hline & Day laborer & $63(15.8)$ \\
\hline
\end{tabular}

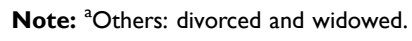

top drug purchased (43.6\%) without prescription and followed by its congeners ampicillin (11.63). Surprisingly, azithromycin, which is a new drug, is one of the top four antibiotics purchased without a prescription. Moreover, metronidazole was also purchased without a prescription (Table 2).

\section{Reasons for Non-Prescription Use of Antibiotics}

In this study, 172 study participants reported using antibiotics without prescription. The study participants were asked the reason for taking antibiotics without prescription while they were expected to use only prescribed ones. One hundred seven $(62.2 \%)$ of the participants use the nonprescribed antibiotics to save time, $111(64.5 \%)$ to save money, $111(64.5 \%)$ to get well soon, $64 \%$ because of previous experience with the same disease, which was successful, $110(64 \%)$ because they assume antibiotics can be purchased without a prescription in pharmacy or drug stores, and 93 (54.1\%) think doctors are likely to prescribe the same type of antibiotics (Figure 1).

The key informants were asked for their opinion on the main reasons that drive for non-prescription use of

Table 2 Antibiotics Purchased Without Prescription, the Antibiotic Use of Ambo Town, Oromia, Ethiopia, 2020 ( $n=399)$

\begin{tabular}{|c|c|c|c|}
\hline $\begin{array}{l}\text { List of Antibiotics } \\
\text { Purchased Without } \\
\text { Prescription }\end{array}$ & $n(\%)$ & $\begin{array}{l}\text { Dosage } \\
\text { Forms }\end{array}$ & $\begin{array}{l}\text { Category } \\
\text { According to } \\
\text { WHO } \\
\text { AWaRe } \\
\text { Classification } \\
\text { of Antibiotics }\end{array}$ \\
\hline Amoxicillin & $75(43.6)$ & Capsule & Access \\
\hline Ampicillin & $20(11.6)$ & Capsule & Access \\
\hline Cotrimoxazole & $15(8.7)$ & Tablet & Access \\
\hline Azitromycin & $13(7.6)$ & Tablet & Access \\
\hline Metrinidazole & $10(5.8)$ & Capsule & Access \\
\hline Tinidazole & $7(4.1)$ & Tablet & $\begin{array}{l}\text { Not available } \\
\text { on the list }\end{array}$ \\
\hline Cloxacillin & $7(4.1)$ & Capsule & Access \\
\hline Augumentin* & $6(3.5)$ & Tablet & Access \\
\hline Cefalexin & $5(2.9)$ & Capsule & Access \\
\hline Tetracycline & $4(2.3)$ & Capsule & Access \\
\hline Ciprofloxacin & $3(1.7)$ & Tablet & Watch \\
\hline Erythromycin & $2(1.2)$ & Tablet & Watch \\
\hline Chloraniphenicol & $2(1.2)$ & Capsule & Access \\
\hline Gyntamicin & $I(0.6)$ & Ointment & Access \\
\hline Cefixin (edit as cefixime) & $\mathrm{I}(0.6)$ & Capsule & Watch \\
\hline Phenoxymethylpenicillin & $I(0.6)$ & Injection & Access \\
\hline Total & $172(100)$ & & \\
\hline
\end{tabular}

Note: *Amoxicillin + clavulanic acid. 

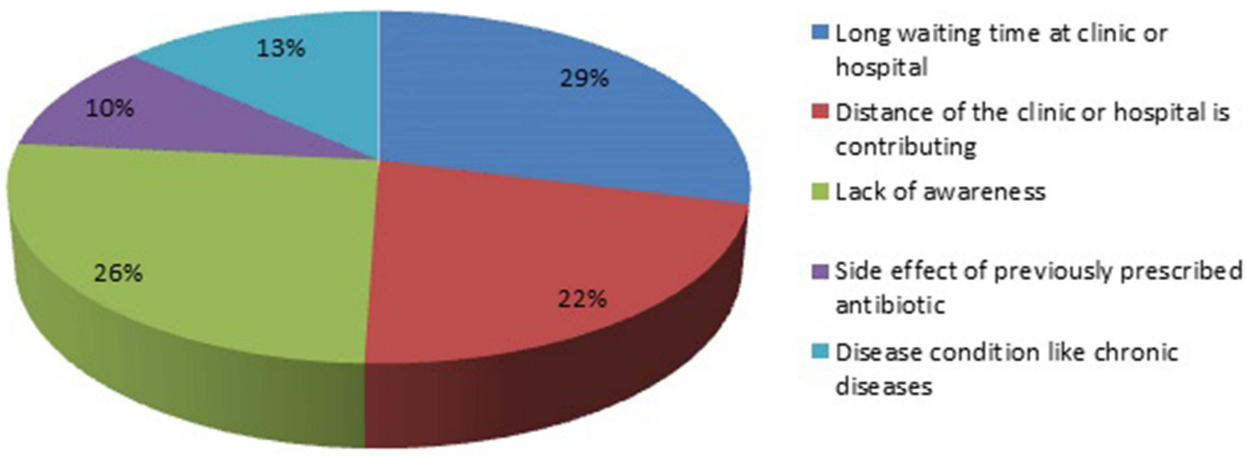

Figure I Reasons reported by key informants for non-prescription use of antibiotics in Ambo Town, West Shoa, Oromia, Ethiopia, 2020.

antibiotics and the majority of them mentioned the lack of health information and previous experience with the same disease.

One of the main problems is long waiting time in hospital, so to save their time as well their money the majority of our customers asked for antibiotics without prescription. (36-year-old woman, Key informant who is working in one drug store)

A 25-year-old man, who was working in one private pharmacy who responded to an in-depth interview said:

I worked in this pharmacy which is located in Ambo as a pharmacist. Even if the majority of our customers are using the prescribed antibiotics there are also a large number of customers who requested for antibiotics without prescription and their probable reasons for considering a non-prescription use of antibiotics may be long waiting time at clinics.

Another 37-year-old man during an in-depth interview stated:

I am working in the drug store as a druggist and also the owner of the drug store, almost 45 to $50 \%$ of our customers ask us to provide them antibiotics without prescription and the majority of them use that due to lack of awareness or lack of health information.

\section{Bivariate and Multivariate Analysis of Factors Associated with Non-Prescription Use of Antibiotics}

According to the results from bivariate binary logistic regression, factors that were associated with non-prescription use of antibiotics are sex, age, marital status, residence, educational status, occupational status, traveling time, type of transportation, and cost of transportation (Table 3).
In the multivariate binary logistic regression marital status, residence (rural), sex (male), educational status (diploma and degree holder), and occupation (farmer) were found to be statistically significant (Table 4).

\section{Discussion}

The current study has assessed the non-prescription use of antibiotics and associated factors in Ambo Town. The study findings revealed that $172(43.1 \%)$ with $(95 \% \mathrm{CI}$ : $38.3,47.9)$ had used non-prescribed antibiotics in the study period. This study finding is consistent with previous studies conducted in Asmara Eritrea $(45.1 \%)^{20}$ and Saudi Arabia (48.5\%). ${ }^{21}$ But the finding of this study is higher than the findings reported from South Ethiopia (14.5\%), ${ }^{22}$ Northwest Ethiopia 23.3\%, ${ }^{23}$ United Arab Emirate $(31.7 \%),{ }^{24}$ and Southwestern Ethiopia $(39 \%){ }^{25}$ This difference in the prevalence of nonprescription use of antibiotics is probably due to the level of awareness about antibiotic use, and definitions used in the studies. However, the results on nonprescription use of antibiotics in the current study are lower than the findings of researches conducted in Zambia $(97 \%){ }^{3}$ India $(66.7 \%),{ }^{26}$ and Riyadh $(77.6 \%) .{ }^{27}$ The prevalent trend of non-prescription use of antibiotics in the developing world has been associated with a lack of access to health care facilities, availability of antibiotics as OTC drugs, poor regulatory practice, and the relatively high prevalence of infectious disease. The differences could also be because of the country's laws on drug procurement or the law enforcement policies of the drug regulatory agencies of the countries where the studies were conducted.

The independently associated factors with nonprescribed antibiotic use were being male, residing in 
Table 3 Bivariate Binary Logistic Regression Analysis of Factors Associated with Non-Prescription Use of Antibiotics in Ambo Town, Oromia, Ethiopia, $2020(n=399)$

\begin{tabular}{|c|c|c|c|c|}
\hline \multirow[t]{2}{*}{ Characteristics } & \multicolumn{2}{|c|}{ Non-Prescribed Antibiotic Use } & \multirow[t]{2}{*}{$\operatorname{COR}(95 \% \mathrm{Cl})$} & \multirow[t]{2}{*}{ P-value } \\
\hline & Yes, n(\%) & No, n(\%) & & \\
\hline \multicolumn{5}{|l|}{ Sex } \\
\hline Male & $99(57.6)$ & $1 \mathrm{I} 5(50.7)$ & $1.32(0.89,1.97)$ & $0.172 *$ \\
\hline Female & $73(42.4)$ & $112(49.3)$ & I & \\
\hline \multicolumn{5}{|l|}{ Age Group (years) } \\
\hline $18-27$ & $74(43)$ & $69(30.4)$ & I & \\
\hline $28-37$ & $40(23.3)$ & $45(19.8)$ & $3.30(1.63,6.69)$ & $0.001 *$ \\
\hline $38-47$ & $30(17.4)$ & $49(21.6)$ & $2.74(1.28,5.83)$ & $0.009 *$ \\
\hline $48-57$ & $15(8.7)$ & $24(10.6)$ & $\mathrm{I} .88(0.87,4.08)$ & $0.108^{*}$ \\
\hline$>57$ & $13(7.6)$ & $40(17.6)$ & $1.92(0.78,4.72)$ & $0.154 *$ \\
\hline \multicolumn{5}{|l|}{ Marital Status } \\
\hline Single & $80(46.5)$ & $79(34.8)$ & I & \\
\hline Married & $84(48.8)$ & 144(63.4) & $0.58(0.38,0.87)$ & $0.009 *$ \\
\hline Others & $8(4.7)$ & $4(1.8)$ & $1.98(0.57,6.82)$ & 0.282 \\
\hline \multicolumn{5}{|l|}{ Residence } \\
\hline Urban & $114(66.3)$ & I77(78) & I & \\
\hline Rural & $58(33.7)$ & $50(22)$ & $1.80(1.15,2.81)$ & $0.010^{*}$ \\
\hline \multicolumn{5}{|l|}{ Educational Status } \\
\hline No formal education & $40(23.3)$ & $45(19.8)$ & I & \\
\hline Elementary school & $45(26.2)$ & $54(23.8)$ & $0.94(0.52,1.68$ & 0.828 \\
\hline Secondary school & $46(26.7)$ & $40(17.6)$ & $1.29(0.71,2.36)$ & 0.401 \\
\hline Diploma & $25(14.5)$ & $37(16.3)$ & $0.76(0.39,1.47)$ & 0.417 \\
\hline Degree and above & 16(9.3) & $5 \mathrm{I}(22.5)$ & $0.35(0.17,0.71)$ & $0.004 *$ \\
\hline \multicolumn{5}{|l|}{ Occupational Status } \\
\hline Government & $23(13.4)$ & $58(25.6)$ & I & \\
\hline Merchant & $34(19.8)$ & $57(25.1)$ & $1.50(0.79,2.86)$ & 0.213 \\
\hline Farmer & $19(11)$ & $55(24.2)$ & $0.87(0.43,1.77)$ & 0.704 \\
\hline Housewife & $23(13.4)$ & $19(8.4)$ & $3.05(1.40,6.63)$ & $0.005^{*}$ \\
\hline Student & $14(8.1)$ & $13(5.7)$ & $2.72(1.11,6.65)$. & $0.029 *$ \\
\hline Non-employed & $14(8.1)$ & $7(3.1)$ & $5.04(1.80,4.10)$ & $0.002^{*}$ \\
\hline Daily laborer & $45(26.2)$ & $18(7.9)$ & $6.30(3.04,3.07)$ & $0.000^{*}$ \\
\hline \multicolumn{5}{|l|}{ Travelling-time $(\min )$} \\
\hline$<15$ & $189(83.6)$ & $117(68)$ & $0.52(0.30,0.88)$ & $0.016^{*}$ \\
\hline $15-30$ & $24(10.6)$ & $43(25)$ & $0.35(0.21,0.59)$ & $0.000 *$ \\
\hline$>30$ & $13(5.8)$ & $12(7)$ & & \\
\hline \multicolumn{5}{|l|}{ Type of Transportation } \\
\hline On foot & $101(58.7)$ & $74(32.6)$ & $2.93(1.94,4.43)$ & $0.000 *$ \\
\hline Use own transport & $2(1.2)$ & $5(2.2)$ & $0.86(0.16,4.53)$ & 0.857 \\
\hline Public transport & $69(40.1)$ & $65.2(148)$ & I & \\
\hline \multicolumn{5}{|l|}{ A Single Trip Cost of Travel (ETB) } \\
\hline$<6$ Birr & $70(30.8)$ & $33(19.2)$ & I & \\
\hline$\geq 6$ Birr & $157(69.2)$ & $139(80.8)$ & $1.34(0.90,1.99)$ & $0.154 *$ \\
\hline
\end{tabular}

Note: *P-value $\leq 0.25$.

Abbreviations: $\mathrm{COR}$, crude odds ratio; $\mathrm{Cl}$, confidence interval. 
Table 4 Multivariable Logistic Regression Analysis and Associated Factors for Non-Prescription Use of Antibiotics in Ambo Town, Oromia, Ethiopia, $2020(n=399)$

\begin{tabular}{|c|c|c|c|c|}
\hline \multirow[t]{2}{*}{ Characteristics } & \multicolumn{2}{|c|}{ Non-Prescribed Antibiotic Use } & \multirow[t]{2}{*}{ AOR(95\% CI) } & \multirow[t]{2}{*}{ P-value } \\
\hline & Yes, n(\%) & No, n(\%) & & \\
\hline \multicolumn{5}{|l|}{ Marital Status } \\
\hline Single & $80(46.5)$ & $79(34.8)$ & 1 & \\
\hline Married & $84(48.8)$ & $144(63.4)$ & $1.21(0.53,2.79)$ & 0.653 \\
\hline Others & $8(4.7)$ & $4(1.8)$ & $8.73(1.61,7.29)$ & $0.012 * *$ \\
\hline \multicolumn{5}{|l|}{ Residence } \\
\hline Urban & $114(66.3)$ & I77(78) & I & \\
\hline Rural & $58(33.7)$ & $50(22)$ & $3.66(1.48,9.05)$ & $0.005^{* *}$ \\
\hline \multicolumn{5}{|l|}{ Sex } \\
\hline Male & $99(57.6)$ & $115(50.7)$ & $2.21(1.28,3.84)$ & $0.005 * *$ \\
\hline Female & $8(4.7)$ & $4(1.8)$ & 1 & \\
\hline \multicolumn{5}{|l|}{ Educational Status } \\
\hline No formal education & $40(23.3)$ & $45(19.8)$ & 1 & \\
\hline Primary school & $45(26.2)$ & $54(23.8)$ & $0.47(0.21,1.08)$ & 0.075 \\
\hline Secondary school & $46(26.7)$ & $40(17.6)$ & $0.89(0.39,2.03)$ & 0.783 \\
\hline Diploma & $25(14.5)$ & $37(16.3)$ & $0.12(0.03,0.59)$ & $0.009 * *$ \\
\hline Degree and above & $16(9.3)$ & $5 \mathrm{I}(22.5)$ & $0.05(0.01,0.38)$ & $0.004 * *$ \\
\hline \multicolumn{5}{|l|}{ Occupation } \\
\hline Government & $23(13.4)$ & $58(25.6)$ & 1 & \\
\hline Merchant & $34(19.8)$ & $57(25.1)$ & $0.19(0.03,1.23)$ & 0.082 \\
\hline Farmer & $19(11)$ & $55(24.2)$ & $0.03(0.00,0.29)$ & $0.002 * *$ \\
\hline Housewife & $23(13.4)$ & $19(8.4)$ & $0.36(0.05,2.88)$ & 0.337 \\
\hline Student & $14(8.1)$ & $13(5.7)$ & $0.18(0.02,1.37)$ & 0.097 \\
\hline Non-employed & $14(8.1)$ & $7(3.1)$ & $2.64(0.63,1.09)$ & 0.187 \\
\hline Day laborer & $45(26.2)$ & I8(7.9) & $0.34(0.05,2.23)$ & 0.260 \\
\hline
\end{tabular}

Notes: **P-value $<0.05$. Others $=$ divorced and widowed.

Abbreviations: $\mathrm{AOR}$, adjusted odds ratio; $\mathrm{Cl}$, confidence interval.

a rural area, divorced and widowed, and holding a diploma and BSc degree. The odds of nonprescription use of antibiotics among male respondents were 2.213 times higher than female respondents. Similar findings have been evidenced in Indonesia, ${ }^{28}$ Asmara Eritrea, ${ }^{20}$ Central Zone of Tigray, Ethiopia, ${ }^{16}$ Saudi Arabia. ${ }^{29}$ This finding was contrary to other studies done in Nigeria, ${ }^{30}$ and the United Arab Emirates. $^{24}$ This difference may be due to the current study context, males have better health-seeking behavior compared to their counterparts.

The odds of non-prescription use of antibiotics among rural dweller respondents were three times more likely as compared to urban residing respondents. This study was similar to the study conducted in Nigeria. ${ }^{31}$ Furthermore, the divorced and widowed were nine times more likely to use non-prescribed antibiotics than those who are single. Moreover, the finding of this study has also shown that level education has a significant association with non-prescription use of antibiotics. Holding Diploma and BSc degree decreases the odds of nonprescribed antibiotics use by $88 \%$, and $95 \%$ respectively as compared to those uneducated. This finding was similar to the studies conducted in Saudi Arabia. ${ }^{29}$ However, this finding was not in line with the finding of a study conducted in Rwanda. ${ }^{32}$ For the occupational status, farmers were $96.6 \%$ less likely to use the nonprescribed antibiotics as compared to those who are government employees. This study finding is similar to studies conducted in the United Arab Emirates. ${ }^{24}$ However, the current study was contrary to the studies conducted in Sudan, which showed professionals have better incomes and thus can afford to pay for health expenses. $^{33}$ 


\section{Limitation of the Study}

Triangulation of data collection methods (both quantitative and qualitative) is the strength of this study, while most previous studies used only quantitative or qualitative study design alone. Lack of temporally relationship and limitation related to selfreport are the two common limitations of the study.

\section{Conclusions}

This study revealed that the majority of the respondents practiced the use of non-prescription antibiotics purchased mainly from drugstores in the town. The groups associated with the use of non-prescription antibiotics were mainly male, residing in rural areas, others (divorced and widowed), diploma and degree holders as well as farmers. The findings emphasize the need to form and deliver comprehensive and multifaceted interventions such as providing tailored education to the public to improve their knowledge about the demerits of using antibiotics without the prescription. Moreover, to improve their attitude towards utilizing a nonprescription antibiotic, it is very important to adopt a strong and explicit line of action on the accessibility of antibiotics without a prescription from any drug retail outlets. This can be achieved through the health bureau communication office by working on public awareness through community-based education on the disadvantages of consuming nonprescription antibiotics, regulating antibiotic distribution channels from pharmaceutical wholesalers to prevent irresponsible sales of antibiotics and prompt law enforcement by regulatory bodies.

\section{Abbreviations}

AMR, antimicrobial resistance; OTC, over the counter; COR, crude odds ratio; AOR, adjusted odds ratio; $\mathrm{CI}$, confidence interval; SD, standard deviation; SPSS, Statistical Package for Social Science; USD, United States dollar.

\section{Data Sharing Statement}

The datasets used and/or analyzed during the current study are available from the corresponding author on reasonable request.

\section{Ethics Approval and Consent to Practice}

This study was conducted in accordance with the Declaration of Helsinki. The study was approved by the ethical committee of Rift Valley University with approval number RVUSop217/2020. Written informed consent was also obtained from the study participants before commencing the study. Participant's information was kept confidential.

\section{Acknowledgments}

The authors would like to acknowledge all the study participants. The authors would also like to acknowledge the school of public health RVU for its unreserved support.

\section{Author Contributions}

All authors made a significant contribution to the work reported, whether that is in the conception, study design, execution, acquisition of data, analysis, and interpretation, or in all these areas; took part in drafting, revising or critically reviewing the article; gave final approval of the version to be published; have agreed on the journal to which the article has been submitted; and agree to be accountable for all aspects of the work.

\section{Funding}

This article is the outcome of an in-house financially nonsupported study.

\section{Disclosure}

The authors declare that they have no competing interests.

\section{References}

1. Van Boeckel TP, Gandra S, Ashok A, et al. Global antibiotic consumption 2000 to 2010: an analysis of national pharmaceutical sales data. Lancet Infect Dis. 2014;14(8):742-750. doi:10.1016/S14733099(14)70780-7

2. Ofori-Asenso R, Agyeman AA. Irrational use of medicines-a summary of key concepts. Pharmacy. 2016;4(4). doi:10.3390/pharmacy4040035

3. Kalungia AC, Burger J, Godman B, de Oliveira Costa J, Simuwelu C. Non-prescription sale and dispensing of antibiotics in community pharmacies in Zambia. Expert Rev Anti Infect Ther. 2016;14 (12):1215-1223. doi:10.1080/14787210.2016.1227702

4. Gonzales R, Bartlett JG, Besser RE, et al. Principles of appropriate antibiotic use for treatment of acute respiratory tract infections in adults. Ann Intern Med. 2001;134(6):479-486. doi:10.7326/00034819-134-6-200103200-00013

5. Machowska A, Stålsby Lundborg C. Drivers of irrational use of antibiotics in Europe. Int J Environ Res Public Health. 2019;16(1):27. doi:10.3390/ijerph16010027

6. Bule MH, Ahmed I, Maqbool F, Anjum ZM. Quinazolinone derivatives as a potential class of compounds in malaria drug discovery. Int J Pharmacol. 2017;13(7):818-831. doi:10.3923/ijp.2017.818.831

7. Self Medication AA. Drug Dependency and Self-Managed Health Care-A Review. INTECH Open Access Publisher.; 2012.

8. Berzanskyte A, Valinteliene R, Haaijer-Ruskamp FM, Gurevicius R, Grigoryan L. Self-medication with antibiotics in Lithuania. Int J Occup Med Environ Health. 2006;19(4):246-253. doi:10.2478/ v10001-006-0030-9 
9. Ocan M, Obuku EA, Bwanga F, et al. Household antimicrobial self-medication: a systematic review and metaanalysis of the burden, risk factors and outcomes in developing countries. BMC Public Health. 2015;15(1):1. doi:10.1186/s12889-015-2109-3

10. Afzal S, Salman F, Hayat T, et al. The determinants of self medications. Ann King Edw Med Univ. 2013;19(1):73-74. doi:10.21649/akemu.v19i1.486

11. Ocan M, Bwanga F, Bbosa GS, et al. Patterns and predictors of self-medication in Northern Uganda. PLoS One. 2014;9(3):e92323. doi:10.21649/akemu.v19i1.486

12. Esimone CO, Nworu CS, Udeogaranya OP. Utilization of antimicrobial agents with and without prescription by out-patients in selected pharmacies in South-eastern Nigeria. Pharm World Sci. 2007;29 (6):655-660. doi:10.1007/s11096-007-9124-0

13. Skliros E, Merkouris P, Papazafiropoulou A, Gikas A. Selfmedication with antibiotics in rural population in Greece: a cross-sectional multicenter study. BMC Fam Pract. 2010;11(1):58. doi:10.1186/1471-2296-11-58

14. Morgan DJ, Okeke IN, Laxminarayan R, Perencevich EN, Weisenberg S. Non-prescription antimicrobial use worldwide: a systematic review. Lancet Infect Dis. 2011;11(9):692-701. doi:10.1016/S1473-3099(11)70054-8

15. Okeke IN, Klugman KP, Bhutta ZA, et al. Antimicrobial resistance in developing countries. Part II: strategies for containment. Lancet Infect Dis. 2005;5(9):568-580. doi:10.1016/S14733099(05)70217-6

16. Gebrekirstos NH, Workneh BD, Gebregiorgis YS, et al. Nonprescribed antimicrobial use and associated factors among customers in drug retail outlet in Central Zone of Tigray, northern Ethiopia: a cross-sectional study. Antimicrob Resist Infect Control. 2017;61:1-10. doi:10.1186/s13756-017-0227-7

17. Gebretekle GB, Serbessa MK. Exploration of over the counter sales of antibiotics in community pharmacies of Addis Ababa, Ethiopia: pharmacy professionals' perspective. Antimicrob Resist Infect Control. 2016;5(1):2. doi:10.1186/s13756-016-0101-z

18. Sisay M, Mengistu G, Edessa D. Epidemiology of self-medication in Ethiopia: a systematic review and meta-analysis of observational studies. BMC Pharmacol Toxicol. 2018;18:1-12. doi:10.1186/ s40360-018-0248-8

19. Gale NK, Heath G, Cameron E, Rashid S, Redwood S. Using the framework method for the analysis of qualitative data in multi-disciplinary health research. BMC Med Res Methodol. 2013;13(1):117. doi:10.1186/1471-2288-13-117

20. Ateshim Y, Bereket B, Major F, et al. Prevalence of self-medication with antibiotics and associated factors in the community of Asmara, Eritrea: a descriptive cross sectional survey. BMC Public Health. 2019;19:726. doi:10.1186/s12889-019-7020-x
21. Belkina T, Al Warafi A, Eltom EH, Tadjieva N, Kubena A, Vlcek J. Antibiotic use and knowledge in the community of Yemen, Saudi Arabia, and Uzbekistan. J Infect Dev Ctries. 2014;8(04):424-429. doi: $10.3855 /$ jidc. 3866

22. Mossa DA, Wabe NT, Angamo MT. Self-medication with antibiotics and antimalarials in the community of Silte zone, South Ethiopia. TAF Prev Med Bull. 2012;11(5):529-536. doi:10.5455/pmb.1-1314892446

23. Mihretie TM. Self-medication practices with antibiotics among urban dwellers of Bahir Dar town, north west Ethiopia; 2014. Available from: http:/localhost:80/xmlui/handle/123456789/1875. Accessed March, 2021.

24. Abduelkarem AR, Othman AM, Abuelkhair ZM, Ghazal MM, Alzouobi SB, El Zowalaty ME. Prevalence of self-medication with antibiotics among residents in United Arab Emirates. Infect Drug Resist. 2019;12:3445-3453. doi:10.2147/IDR.S224720

25. Suleman S, Ketsela A, Mekonnen Z. Assessment of self-medication practices in Assendabo town, Jimma zone, southwestern Ethiopia. Res Social Adm Pharm. 2009;5(1):76-81. doi:10.1016/j.sapharm.2008.04.002

26. Shet A, Sundaresan S, Forsberg BC. Pharmacy-based dispensing of antimicrobial agents without prescription in India: appropriateness and cost burden in the private sector. Antimicrob Resist Infect Control. 2015;4(1):55. doi:10.1186/s13756-015-0098-8

27. Abdulhak AA, Al Tannir MA, Almansor MA, et al. Non prescribed sale of antibiotics in Riyadh, Saudi Arabia: a cross sectional study. BMC Public Health. 2011;11(1):1. doi:10.1186/1471-2458-11-538

28. Hadi U, Duerink DO, Lestari ES, et al. Survey of antibiotic use of individuals visiting public healthcare facilities in Indonesia. Int J Infect Dis. 2008;12(6):622-629. doi:10.1016/j.ijid.2008.01.002

29. Al-Qahtani MA, Amin HS, Al-Qahtani AA, et al. Self-medication with antibiotics in a primary care setting in King Khalid University Hospital, Riyadh, Saudi Arabia. 2018;25. J Family Community Med. 2018;25(2):95-101. doi:10.4103/jfcm.JFCM_124_17

30. Esan DT, Fasoro AA, Odesanya OE, Esan TO, Ojo EF, Faeji CO. Assessment of self-medication practices and its associated factors among undergraduates of a private university in Nigeria. J Environ Public Health. 2018;2018:1-7. doi:10.1155/2018/5439079

31. Abdulraheem I, Adegboye A, Fatiregun A. Self-medication with antibiotics: empirical evidence from a Nigerian rural population. $\mathrm{Br}$ $J$ Pharm Res. 2016;11(5):1-13. doi:10.9734/BJPR/2016/25268

32. Tuyishimire J, Okoya F, Adebayo AY, Humura F, Lucero-Prisno DE III. Assessment of self-medication practices with antibiotics among undergraduate university students in Rwanda. Pan Afr Med. 2019;33:307. doi:10.11604/pamj.2019.33.307.18139

33. Elhada AH, Eltayeb IB, Mudawi MM. Patterns of self-medication with antibiotics in Khartoum State, Sudan. World $J$ Pharm Res. 2014;3(5):678-692.
Patient Preference and Adherence

\section{Publish your work in this journal}

Patient Preference and Adherence is an international, peer-reviewed, open access journal that focusing on the growing importance of patient preference and adherence throughout the therapeutic continuum. Patient satisfaction, acceptability, quality of life, compliance, persistence and their role in developing new therapeutic modalities and compounds to optimize clinical outcomes for existing disease states are major areas of interest for the journal. This journal has been accepted for indexing on PubMed Central. The manuscript management system is completely online and includes a very quick and fair peer-review system, which is all easy to use. Visit http:// www.dovepress.com/testimonials.php to read real quotes from published authors. 